\title{
Article
}

\section{Ion Exchange Behavior of Some Metal Ions on Chemically Modified Biowastes}

\author{
Rabindra Prasad DHAKAL, Kedar Nath GHIMIRE, Katsutoshi INOUE \\ Department of Appied Chemistry, Saga University, Saga 840-8502, Japan. \\ Kenjiro MAKINO \\ Yamasoh Micron Inc., Kogawa, Wakayama 649-6561, Japan
}

(Manuscript submitted January 21, 2003; accepted April 18, 2003)

\begin{abstract}
Recently much attention is given to the environmental friendly and sustainable separation process for the treatment of heavy metals. Recycling of natural materials in order to reduce the organic pollution in one hand and cost effective treatment processes by the application of such natural biowastes on the other, are the main focuses of the present investigation. Experimental results revealed that after simple chemical modification by means of saponification, apple and orange juice residues can be potentially applied for the removal of heavy metals from environment.
\end{abstract}

\section{Introduction}

There is a growing interest of using low cost materials for the treatment of heavy metals in particularly with the effective usage of biomass wastes. Large volumes of industrial and municipal wastewater frequently contain heavy metals that pose threat to human health and living beings. To date, wastewater containing heavy metals are being treated by means of precipitation, sedimentation, coagulation/floatation, filtration, membrane process, and adsorption via ion exchange. Many researchers are attracted with synthetic resin as it effectively adsorbs heavy metal ions. However, since the treatment cost by using chelating resin is relatively high, the uses of low cost materials as adsorbents for such purpose should be employed. In an attempt to reduce the prices of wastewater treatment, biomass wastes such as apple waste and orange wastes are chemically modified to improve their ion exchange behavior.

\section{Experimental}

\subsection{Preparation of saponificated orange and apple juice residue (SOJR and SAJR)}

Crude orange waste was provided from JA Saga Beverage Co. Ltd, Saga, Japan, just after juicing. The orange juice waste is principally composed of cellulose, hemicellulose, pectin substances, limonene, chlorophyll pigments and other low molecular weight compounds.[1] The active binding sites for metals are supposed to be the carboxylic groups in pectin substances. In order to convert the methyl ester part of pectin substances into carboxyl groups, saponification process has been carried out using calcium hydroxide as follows. 


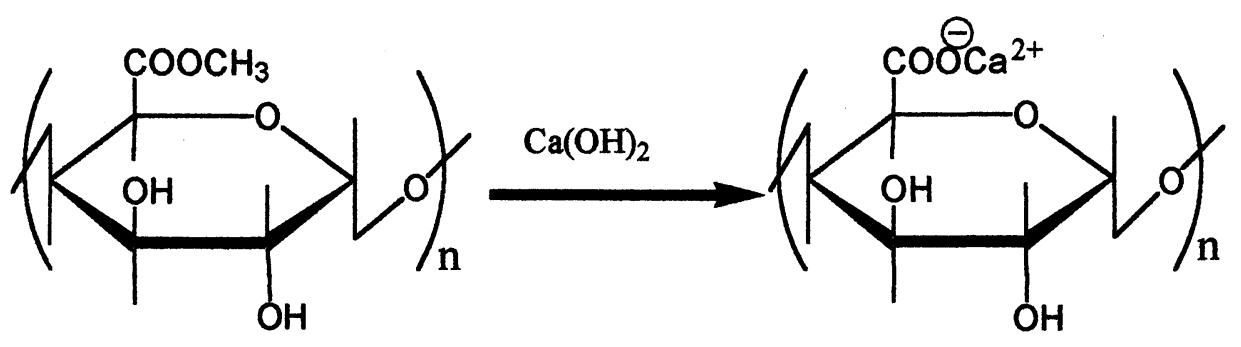

The crude orange juice wastes mixed with calcium hydroxide were milled into fine particles. It is remarkable that the use of calcium hydroxide not only facilitates the saponification but also enables to bleach out chlorophyll pigments and other low molecular weight compounds that are useless for adsorption. The saponificated gel was washed with deionized distilled water followed by decantation up to neutral pH.[2] Finally, the remaining volume of washed gel was vacuum filtered. Saponificated apple juice residue (SAJR) was prepared according to the exactly same manner.

\subsection{Preparation of $\mathbf{H}^{+}$-form SOJR gel}

The saponificated wet cake originally in a $\mathrm{Ca}^{2+}$-form was washed with a $0.1 \mathrm{~mol} \mathrm{dm}^{-3}$ hydrochloric acid solution for $2 \mathrm{~h}$. The suspension of SOJR was washed till neutrality was achieved with distilled water by decantation, and then was filtered. Thus obtained $\mathrm{H}^{+}$- form gel was dried and used to evaluate the maximum exchangeable cations. $50 \mathrm{mg}$ of dried $\mathrm{H}^{+}$-form gel and $30 \mathrm{~cm}^{3}$ of $0.01 \mathrm{~mol} \mathrm{dm}$-3 of sodium hydroxide solutions were taken into five separate stoppered bottles, and was equilibrated for 24 hours of $30^{\circ} \mathrm{C}$. The decrease in pH was evaluated by titrating the filtrate with a $0.01 \mathrm{~mol} \mathrm{dm}^{-3}$ hydrochloric acid solution standardized by using phenolphthalein as an indicator.

\subsection{Chemicals}

All chemicals used were of pure analytical grade purchased from Katayama Chemical Co. Ltd. Japan, unless otherwise mentioned. Aqueous solutions of metal ions were prepared by dissolving corresponding analytical grade metal chlorides or nitrates in dilute nitric or hydrochloric acid solution.

\subsection{Procedure}

$25 \mathrm{mg}$ of dried adsorbent was taken into a conical flask together with a $15 \mathrm{~cm}^{3}$ portion of aqueous model solution containing a corresponding single metal ion. The $\mathrm{pH}$ of the aqueous solutions was adjusted adding small amount of hydrochloric acid or sodium hydroxide, while just in the case of iron(III) adsorption, 2-[4-(2Hydroxyethyl)-1-piperazinyl] ethanesulphonic acid (HEPES) was used as the buffer reagent. The flask was shaken vigorously in a thermostated shaker maintained at $30^{\circ} \mathrm{C}$ for about $24 \mathrm{~h}$ to attain equilibrium. The concentrations of the corresponding metal ion before and after adsorption were measured by using Shimadzu model ICPS-5000 ICP/AES spectrometer or Shimadzu model AA-6650 atomic absorption spectrophotometer.

\section{Results and Discussion}

\subsection{Evaluation of exchangeable cations}

The amount of exchangeable cation contained in $\mathrm{H}^{+}$-form of SOJR gel was evaluated as $2.64 \mathrm{~mol} \mathrm{~kg}{ }^{-1}$. A similar analysis was made for pure pectic acid, which showed $5.65 \mathrm{~mol} \mathrm{~kg}^{-1}$. These results suggest that, instead of using pure pectic acid, a comparatively much cheaper adsorbent having the same functional analog can be prepared by a very simple method of the saponification of orange waste, which might be applied for the purpose of removing toxic heavy metals and recovering of valuable metals. 


\subsection{Adsorption of metal ions on SOJR and SAJR gels}

Figure 1 shows the effect of $\mathrm{pH}$ on the adsorption of various metal ions by $\mathrm{Ca}^{2+}$-form saponificated orange juice residue (SOJR) at an initial concentration of $1 \mathrm{mmol} \mathrm{dm}{ }^{-3}$. The selectivity order is $\mathrm{Pb}^{2+}>\mathrm{Fe}^{3+}>\mathrm{Cu}^{2+}>\mathrm{Cd}^{2+}$ $>\mathrm{Zn}^{2+}>\mathrm{Mn}^{2+}$, while adsorption of iron(III) is highest at $\mathrm{pH}>3$. Figure 2 shows the effect of equilibrium $\mathrm{pH}$ on adsorptive removal of metal ions with $\mathrm{H}^{+}$-form saponificated gel, where the selectivity order is $\mathrm{Pb}^{2+}>\mathrm{Fe}^{3+}>\mathrm{Cu}^{2+}$ $>\mathrm{Zn}^{2+}>\mathrm{Cd}^{2+}>\mathrm{Mn}^{2+}>\mathrm{Ca}^{2+}$ at low $\mathrm{pH}$. The higher removal percentage of iron(III) appears in Fig.1, which may be attributable to two operating processes, 1) adsorption due to ion exchange and 2) coprecipitation of adsorbed iron(III) with calcium ions at high $\mathrm{pH}$. The enhanced removal efficiency may be attributed to an increase in the effective binding strength of the coprecipitated surface and/or the formation of mixed metal hydroxides whose characteristics are different from parent hydroxides.[3]

On the other hand, as shown in Fig.2, the adsorption of iron(III) decreases rapidly with increasing $\mathrm{pH}$, when the $\mathrm{pH}$ is greater than 3 . This is attributable to rapid hydrolysis of iron(III) ions which can not be adsorbed through ion exchange mechanism, as the gel was initially of $\mathrm{H}^{+}$-form. This result is in agreement with the remarks obtained in our previous paper.[4] However, there are still some discrepancies regarding the selectivity order of zinc in Fig.2, as adsorption of cadmium would normally be expected higher. Digestion of SOJR by strong acid showed that the calcium content on the gel was $1.36 \mathrm{~mol}$ $\mathrm{kg}^{-1}$. On the other hand, the extent of exchangeable cations evaluated from the $\mathrm{H}^{+}$form of SOJR was $2.64 \mathrm{~mol} \mathrm{~kg}^{-1}$, indicating that two hydrogen ions are substituted for the exchange of one $\mathrm{Ca}^{2+}$ ions.

Figure 3 shows the percentage adsorption of iron(III), lead(II), copper(II), and cadmium(II), respectively, on saponificated apple juice residue (SAJR) at an initial

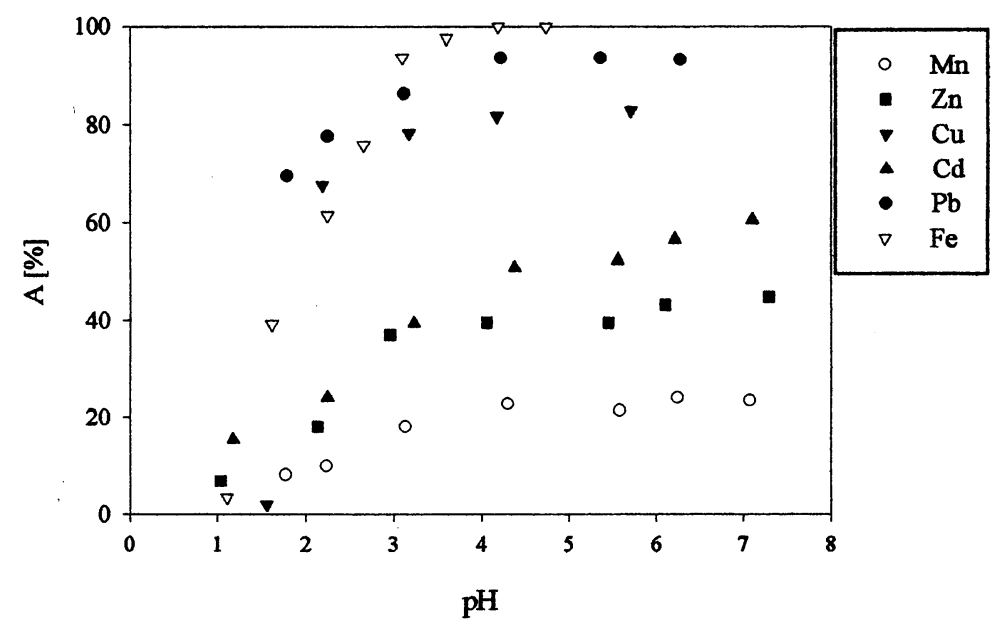

Fig.1 Adsorption of some metal ions on $\mathrm{Ca}^{2+}$-form SOJR. Weight of the gel $=25 \mathrm{mg}$,

Volume of the aqueous solution $=15 \mathrm{~cm}^{3}$, Initial metal concentration $=1 \mathrm{mmol} \mathrm{dm}^{-3}$.

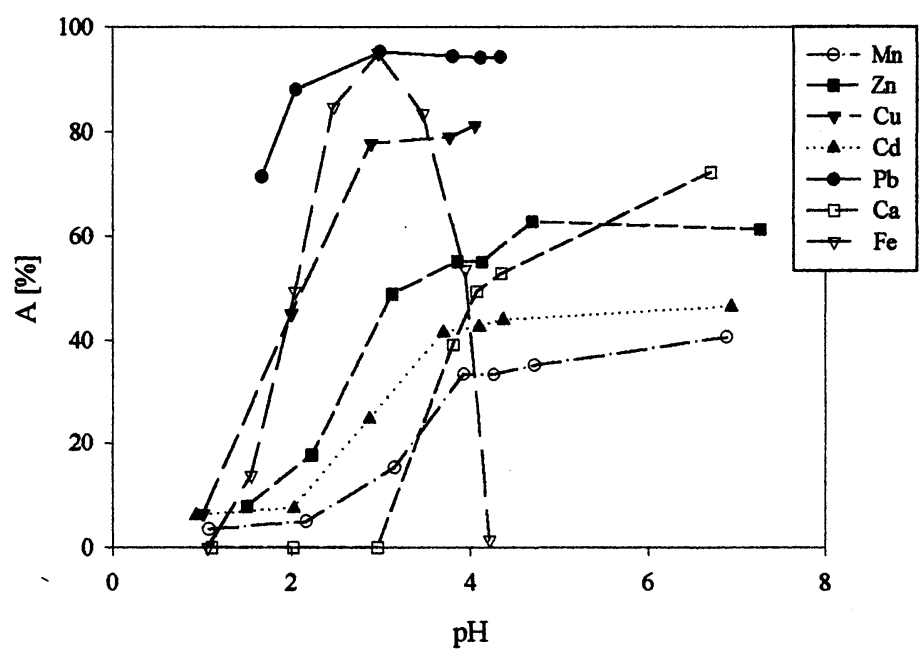

Fig.2 Adsorption of some metal ions on $\mathrm{H}^{+}$-form SOJR.

Weight of the gel $=25 \mathrm{mg}$,

Volume of the aqueous solution $=15 \mathrm{~cm}^{3}$, Initial metal concentration $=1 \mathrm{mmol} \mathrm{dm}^{-3}$. 
concentration of $1 \mathrm{mmol} \mathrm{dm}^{-3}$ as the functions of $\mathrm{pH}$. In this case, selectivity for iron(III) is the highest as compared to others, which is different with the case in SOJR. This might be due to comparatively low pectic acid content in SAJR. Nevertheless, mutual separations of the tested metal ions are excellent on the SAJR.

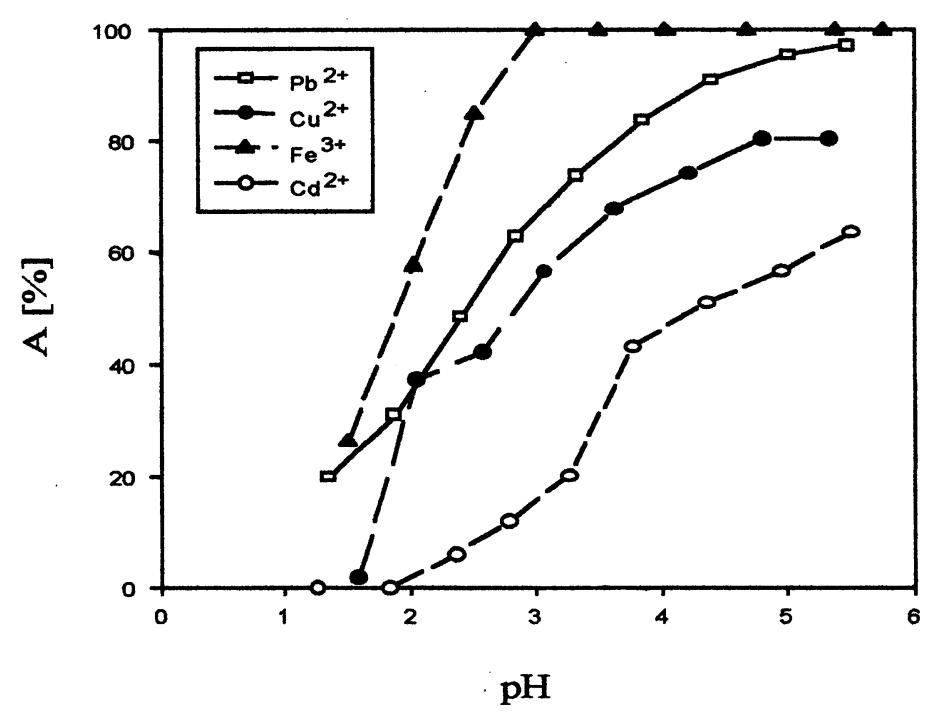

Fig.3 Adsorption of some metal ions on $\mathrm{Ca}^{2+}$-form SAJR. Weight of the gel $=25 \mathrm{mg}$, Volume of the aqueous solution $=15 \mathrm{~cm}^{3}$, Initial metal concentration $=1 \mathrm{mmol} \mathrm{dm}$.

\section{Acknowledgement}

The present work was conducted with the aid of financial support from the Japan Science and Technology Corporation as the Modeling Project for New Concepts of Technology.

\section{References}

1) S. Nagy, P. E. Shaw and M. K. Veldhuis, The AVI Publishing Company, Inc Westport, Connecticut (1977), Chap.3-11 pp.74-427.

2) K. N. Ghimire, Ph. D thesis, Saga University, 2002, 155-169.

3) R. J. Crawford, I. H. Harding and D. E. Mainwaring, Langmuir, 9, 3050-3062 (1993).

4) K. N. Ghimire, K. Inoue, K. Makino and T. Miyajima, Sep. Sci. Technol., 37, 2785-2799 (2002). 